\title{
Patients with psychoactive substance use disorders treated in a psychiatric emergency unit
}

\author{
Pacientes com transtornos relacionados ao uso de substâncias psicoativas atendidos \\ em uma unidade de emergência psiquiátrica
}

Vitoria M. Padilha ${ }^{1}$, Amilton dos Santos-Júnior ${ }^{2}$, Carolina S. S. Schettini ${ }^{3}$, Renata C. S. Azevedo

\begin{abstract}
Study type: Prevalence study. Objective: To describe the socio demographic and clinical profile of patients with mental and behavioral disorders due to psychoactive substance (PAS) use, evaluated by the Psychiatric team of the Referenced Emergency Unit (REU) at the State University Clinical Hospital of Campinas (UNICAMP-HC). Methods and casuistic: This is a descriptive and quantitative study, which analyzed patients with mental and behavioral disorders due to PAS use, evaluated by the Psychiatric team of the REU-HC-UNICAMP during a period of 12 months, starting on May 2010. Results: There were evaluated 350 patients with PAS related disorders, representing $23.8 \%$ of those who sought psychiatric care. Most were males and younger than other patients of the emergency unit. The main reason for seeking help was psychiatric complaint other than PAS related disorders (23.1\%), followed by desire to be treated oneself/being admitted to inpatient psychiatric treatment (20.8\%) and intoxication $(12.5 \%) ; 38.5 \%$ had a diagnosis of multiple PAS dependence and $34.8 \%$ were diagnosed with isolated alcohol dependence; $36 \%$ had psychiatric comorbidities and, when compared to other patients, they received more medications during attendance and were less directed to primary care units. Conclusion: There is a high rate of consultations of patients with PAS related problems in the psychiatric emergency unit. Data on the profile of the evaluated these patients can contribute to the improvement of care to this population.
\end{abstract}

Key Words: Emergency Medical Services. Emergency Services, Psychiatric. Alcohol-Related Disorders. Substance-Related Disorders. Street Drugs.

1. Médica Psiquiatra - Mestre em Ciências Médicas - Faculdade de Ciências Médicas - Universidade Estadual de Campinas (FCM-Unicamp)

2. Professor Doutor - FCM-Unicamp

3. Médica - FCM-Unicamp

4. Professora Doutora - FCM-Unicamp
Correspondencia

Amilton dos Santos Jr

Faculdade de Ciências Médicas Universidade Estadual de Campinas

Recebido em 02/10/2014 Aprovado em 14/10/2015

Individual contributions:

All authors had significantly contributed to the conception and design of the study, to the analysis and interpretation of data and to the elaboration of the article:

Vitoria Mantoan Padilha: contributed substantially in all stages of study planning, data analyzing and article writing.

Carolina Silva Said Schettini: contributed to the collection, analysis and interpretation of data.

Amilton dos Santos Jr: contributed to the collection, analysis and interpretation of data and in the review of the manuscript.

Renata Cruz Soares de Azevedo: main responsible for designing and planning the study, besides analyzing data and critically reviewing the content of the manuscript.

All authors approved the final version.

Conflicts of interest: The authors declare no conflict of interest. 


\begin{abstract}
RESUMO
Modelo do Estudo: Estudo de prevalência. Objetivo: Descrever o perfil sócio demográfico e clínico de pacientes com transtornos relacionados ao uso de substâncias psicoativas (SPA) atendidos pela Psiquiatria da Unidade de Emergência Referenciada (UER) do Hospital de Clínicas (HC) da UNICAMP. Métodos e casuística: Estudo descritivo e quantitativo, que avaliou os pacientes com transtornos relacionados ao uso de SPA atendidos pela Psiquiatria da UER do HC-UNICAMP no período de 12 meses a partir de maio de 2010. Resultados: Foram avaliados 350 pacientes com transtornos por uso de SPA, representando $23.8 \%$ do total dos que procuraram atendimento psiquiátrico. Maioria do sexo masculino e mais jovens do que os demais pacientes. O principal motivo de atendimento foi queixa psiquiátrica outra que não o uso de SPA (23,1\%), seguido do desejo de se tratar/internar (20,8\%) e intoxicação $(12,5 \%)$. $38,5 \%$ tinham diagnóstico de dependência de múltiplas SPA e 34,8\% dependência exclusiva de álcool; $36 \%$ apresentavam comorbidade psiquiátrica. Quando comparados com os demais pacientes avaliados pela Psiquiatria, receberam mais medicações no atendimento e foram menos encaminhados à atenção primária. Conclusão: Há elevada taxa de atendimento de pessoas com problemas relacionados ao uso de SPA na emergência psiquiátrica. Dados sobre o perfil dos atendidos podem contribuir para a melhoria da assistência a esta população.
\end{abstract}

Palavras-chave: Serviços Médicos de Emergência. Serviços de Emergência Psiquiátrica. Transtornos Relacionados ao Uso de Álcool. Transtornos Relacionados ao Uso de Substâncias. Drogas Ilícitas.

\section{Introduction}

Consumption and dependence on psychoactive substances (PAS) represent an important risk factor for several diseases globally. A report of the World Health Organization indicated that $9 \%$ of the global volume of diseases result from the consumption of PAS. ${ }^{1}$ It is estimated that psychoactive substances, both licit and illicit, contributed with 12.4 $\%$ of all deaths worldwide in 2000 , and the percentage of years lost due to the use of these substances is $8.9 \% .^{2}$ Regarding alcohol, $4 \%$ of deaths worldwide are attributed to its problematic use, due to trauma, neuropsychiatric disorders, cardiovascular conditions and cancer. ${ }^{3}$ The United Nations Office on Drugs and Crime estimates that in 2010 there were between 99,000 to 253,000 deaths that resulted from the use of illegal drugs. ${ }^{4}$ Studies show that PAS users tend to seek the routine and preventive medical care consultations less, seeking preferably hospitals and emergency services to treat both physical and mental problems, triggered by the consumption of PAS. ${ }^{5}$

It is estimated that only $20 \%$ of illicit drug users worldwide received some type of treatment in 20104. For most users and dependents on PAS, the Emergency Room (ER) is the only medical care provider. ${ }^{6}$ Studies show prevalence of abuse or dependence of PAS in approximately $20 \%$ of all patients that seek treatment at the emergency rooms, ${ }^{6,7}$ and
$30 \%$ among those who are treated in the Psychiatric Emergency Departments (PED). ${ }^{8}$ A prospective study conducted in a tertiary Emergency Room Unit in Canada showed that $59 \%$ of patients who had been treated by the psychiatric team were diagnosed with primary or secondary substance dependence. ${ }^{9}$ North American data indicate that there is an increasing tendency in emergency admissions at the Emergency Rooms due to PAS related-disorders, being more significant in relation to illicit substances. ${ }^{10}$

Patients with PAS use disorders, when compared to patients who seek Emergency Rooms for other reasons, are younger. ${ }^{7}$ However, they remain longer in the Emergency Rooms and are more likely to be hospitalized and seek emergency treatment again next year, ${ }^{7}$ which shows the important role of these units and emergency rooms in the detection and intervention when treating PAS abuse and dependence.

Due to the tendency of the increasing demand of patients with disorders related to the use of PAS seeking treatment in the emergency room, it is necessary to know the profile of this population, in order to optimize and to adjust the treatment offered. The objective of this study is to describe the demographic and clinical profile of patients with disorders related to the use of psychoactive substances (PAS) attended by the Referenced Emergency Unit (REU) of the State University Clinical Hospital of Campinas (UNICAMP-HC). 


\section{Materials and Methods}

\section{Type of Study}

This is a descriptive and quantitative study, which evaluated patients with disorders related to the use of psychoactive substances attended by the Psychiatric Department of the REU, HC-UNICAMP during 12 months, starting on May 2010.

\section{Local}

The REU from HC-UNICAMP provides medical care of high complexity for the city of Campinas and its vicinities, covering a population of about $3,000,000$ inhabitants. The main objective of the REU is the specialized emergency and urgency medical care. The service flow rate of the REU is 200 patients of more than 14 years-old per day, on average. The service, very similar to other emergency care units, is organized to operate 24 hours a day without interruption, to meet anyone who seeks, without prior appointment or consultations' limit. ${ }^{11}$

The socio-demographic data were collected from medical records of patients attended by the Psychiatric Service of the REU of HC-UNICAMP. The REU was the only psychiatric emergency unit in the area at the time of the study. The referral to the REU is done primarily through telephone contact by the Medical Emergency Rescue Service (SAMU) or the Regulatory Center of the Regional Health Directorate and its municipalities. Spontaneous demand patients are also attended and in this case, the criterion of seriousness is respected in order to determine the order of attendance. Prior to medical treatment, patients undergo a screening performed by the nursing teams, in which the patients with serious cases have priority in attendance. Only the cases attended by the Orthopedics or Psychiatric Department do not go through this screening and patients are attended directly by its specific specialty. The psychiatric care is done by doctors from the Medical Residency Program in Psychiatry, accompanied by medical students and supervised on site by a Psychiatrist, every day of the week, 24 hours a day.

\section{Study Participants}

Patients with PAS use disorders who sought treatment through the REU Psychiatric Department of the HC-UNICAMP during 12 months, starting on May 2010.

Inclusion criteria: patients older than 18 years of age, of both sexes, attended by the Department of Psychiatry of the REU during the period from May 2010 through May 2011 that showed in their anamnesis a history of abuse or dependence on any kind of PAS, or if the diagnosis hypothesis contained abuse, addiction or psychiatric disorders induced by PAS use, even if the psychoactive substance disorder was not necessarily the primary reason for the consultation.

Exclusion criteria: recurrent visits during the study period, given that only the first attendance for each patient was considered.

\section{Outcomes of interest}

Of all the patients treated in the REU Psychiatric Department during this period, the following data were collected from medical records: gender, age, source of referral, reason for coming to the REU, diagnosis recorded at the end of the evaluation, whether any medication, including psychotropic, had been prescribed, and, if so, which ones, and which were the referrals and home prescriptions.

These data were further analyzed by comparing the patients users of PAS with patients diagnosed with other psychiatric disorders attended by Psychiatry during the study period. Of the patients attended due to PAS related disorders the following informations were also collected from the medical records: PAS usage pattern, presence of diagnose of PAS use, abuse or dependence, presence and type of psychiatric comorbidity.

\section{Data Analysis}

The collected data were entered into a database of the SAS System for Windows program, version 9.2. To assess the relationship between categorical variables there were used the Qui-square and Fischer exact tests (for expected values of less than 5).

\section{Procedures}

From May 2010 to May 2011, the records of all patients who sought treatment at the REU Psychiatric Department of the HC-UNICAMP were separated weekly and data were transferred from the data collection form to build the database. 
The data collection form utilized for data collection was elaborated using review of the medical records of the REU, and it included the variables of interest. A pilot study that surveyed 50 medical records of Psychiatric Department of the REU was conducted, aiming to adapt and standardize data collection.

All the reasons described at the beginning of the consultation were analyzed (noted by the resident in the field of "main complaint") and the diagnostic hypotheses set by the doctor at the end of treatment.

In the field reserved for the reasons for treatment, it was defined as "psychiatric complaint" any symptom of psychiatric order other than the consumption of PAS (e.g., depressive symptoms, anxiety, insomnia).

It was determined that the patient had psychiatric comorbidity when another psychiatric disorder was explicitly cited in the diagnostic hypotheses. In source of referral, patients coming from therapeutic communities were placed in the field of "other services".

In the pilot phase, groupings of reasons and diagnostic hypotheses were defined, thereby standardizing the data collection to build the database. In the same way, categories related to the source of referral, medication prescriptions and referrals were standardized.

Throughout data collection, doubts about the suitability of the raw data collected from the records of the REU were discussed between the undergraduate student (CSSS), a psychiatrist at the Psychiatric Service REU (ASJ), the first author of the paper (VMP) and the supervisor of the project (RCSA).

The research project was approved by the Ethics Committee of the FCM-UNICAMP (number 269/2010). The participants were not identified in this study, which analyzed data already contained in records.

\section{Results}

In the period from 25 May 2010 to 31 May 2011, there were 70,137 consultations at the REU HC-UNICAMP, ie, 189 consultations per day on average. Of these, 1835 (2.6\%) were treated by Psychiatry, corresponding to 1465 consultations, or 5 a day on average. Among these patients, 358 pa- tients were treated due to PAS related-disorders. Excluding those under 18 years of age, 350 (23.8\% of the total attended by Psychiatry) were studied. 16 of these patients had disorders related to the use of PAS as comorbidity (was not the primary diagnosis).

There was a marginal tendency in the direction of a higher volume of admissions of patients with disorders related to the use of PAS during the study, when the 1st semester of data collection of this study ( $n=157$ patients) and the 2 nd semester ( $n=188$ patients $)(p=0.05)$ were compared.

Table 1 shows the profiles of patients with disorders related to the use of PAS, when compared to those treated by other psychiatric diagnoses.

The patients with PAS use disorders were most men $(79,1 \%$ versus $34,3 \%, p<0,0001)$, younger $(34,9$ years old versus 37,9 years old, $p=0,020)$ and received more psychiatric medication in the ER $(32,2 \%$ versus $20,7 \%, p=0,000)$, comparing to the other patients attended by REU psychiatric team. Only $5.8 \%$ of patients with PAS use disorders were referred to primary care, versus $29.3 \%$ of patients with other diagnoses.

Table 2 shows the reasons reported by patients to seek treatment and diagnoses established during the treatment provided to PAS users seen at the Emergency Rooms.

Among the patients with disorders related to the use of PAS, the most frequent reason for medical care was psychiatric complaint $(23,1 \%)$, the second was willingness to treat/hospitalize $(20,8 \%)$ and the third was intoxication (12,5\%). The most frequent diagnoses related to PAS use were dependence of multiple PAS (38.5\%) and exclusive dependence on alcohol (34.8\%). Psychiatric comorbidity rate was $36 \%$.

\section{Discussion}

This study points that PAS use disorders motivated $1 / 4$ of Psychiatric Emergency care in a University Service that cover a region with a population of about 3,000,000 inhabitants. Most patients were male, more than half sought care spontaneously, one in five expressed willingness to treat as the reason for seeking emergency care, more than one-third were dependent of multiple PAS and had psychiatric comorbidity. 
Table 1: Comparison between patients with PAS use disorders to other patients attended by REU psychiatric team.

\begin{tabular}{|c|c|c|c|c|c|}
\hline \multirow[b]{2}{*}{ Variables } & \multicolumn{2}{|c|}{$\begin{array}{l}\text { With PAS use disorders } \\
(n=350)\end{array}$} & \multicolumn{3}{|c|}{$\begin{array}{l}\text { Without PAS use disorders } \\
\qquad(n=1115)\end{array}$} \\
\hline & $\boldsymbol{N}$ & $\%$ & $\mathbf{N}$ & $\%$ & $\boldsymbol{P}$ \\
\hline \multicolumn{6}{|l|}{ Gender } \\
\hline Male & 277 & 79.1 & 383 & 34.3 & $<0.0001$ \\
\hline Female & 61 & 17.4 & 683 & 61.2 & \\
\hline Mean age (in years) & 34,9 & 11 & 37,9 & \pm 14 & 0.0020 \\
\hline \multicolumn{6}{|l|}{ Source of referral $(n=1271)$} \\
\hline Spontaneous & 137 & 65.2 & 732 & 68.9 & \\
\hline Emergency Rooms & 30 & 14.2 & 148 & 13.9 & \\
\hline Brought by the family & 13 & 6.1 & 79 & 7.4 & 0.0004 \\
\hline SAMU & 10 & 4.7 & 58 & 5.4 & \\
\hline Other services & 16 & 7.6 & 38 & 3.5 & \\
\hline Medicated in the ER $(n=351)$ & 104 & 33.8 & 247 & 23.2 & 0.000 \\
\hline Psychiatric medication in the ER $(n=306)$ & 89 & 32.2 & 217 & 20.7 & 0.000 \\
\hline \multicolumn{6}{|l|}{ Prescribed medications in the ER } \\
\hline Benzodiazepinic & 67 & 21.2 & 163 & 15.3 & 0.014 \\
\hline Antipsychotic & 33 & 10.4 & 118 & 11.1 & 0.746 \\
\hline B Complex / Thiamine & 32 & 10.1 & 7 & 0.7 & 0.000 \\
\hline Promethazine & 2 & 0.6 & 47 & 4.4 & 0.001 \\
\hline \multicolumn{6}{|l|}{ Prescribed medications for home } \\
\hline Benzodiazepinic & 112 & 35.4 & 331 & 31.2 & 0.153 \\
\hline Antipsychotic & 32 & 10.1 & 193 & 18.2 & 0.001 \\
\hline B Complex / Thiamine & 16 & 5.1 & 1 & 0.1 & 0.000 \\
\hline Antidepressant & 22 & 7 & 209 & 19.7 & 0.000 \\
\hline Mood stabilizer & 8 & 2.5 & 40 & 3.8 & 0.293 \\
\hline \multicolumn{6}{|l|}{ Referrals } \\
\hline Basic Public Health Care $(n=1386)$ & 19 & 5.8 & 311 & 29.3 & $<0.0001$ \\
\hline CAPS* $(n=1386)$ & 13 & 3.9 & 84 & 7.9 & 0.0148 \\
\hline CAPS-AD** $(n=1386)$ & 25 & 7.6 & 10 & 0.9 & $<0.0001$ \\
\hline Psychiatric Hospitalization $(n=1387)$ & 25 & 7.6 & 65 & 6.1 & 0.3228 \\
\hline Inpatient care $(n=1386)$ & 10 & 3.0 & 0 & 0.0 & $<0.0001$ \\
\hline ASPA*** $(n=1398)$ & 190 & 56.3 & 14 & 1.3 & $<0.0001$ \\
\hline Other Outpatient Care of HC $(n=1395)$ & 53 & 15.8 & 308 & 29 & $<0.0001$ \\
\hline
\end{tabular}

* Psychosocial Care Center (CAPS)

** Drug and alcohol Psychosocial Care Center (CAPS-AD)

*** Psychoactive Substances Outpatient Clinic (ASPA) of HC-UNICAMP 
Table 2: Reason for medical care and diagnostic profile of patients with conditions related to the use of PAS $(n=350)$

\begin{tabular}{llr} 
Variable & N & \% \\
\hline Reason for Medical Care & & 23.1 \\
Psychiatric complaint & 81 & 20.8 \\
Willingness to treat / hospitalize & 73 & 12.5 \\
Intoxication & 44 & 11.1 \\
Complaints related to PAS use & 39 & 8.5 \\
Withdrawal & 30 & 6.0 \\
Clinical complaints other/accidents & 21 & 5.4 \\
Suicide attempts & 19 & 4.5 \\
Brought by the family & 16 & 7.7 \\
Missing data & 27 &
\end{tabular}

\section{Diagnostic profile related to PAS use}

Exclusive dependence on alcohol

$135 \quad 38.5$

Exclusive dependence on cocaine

$122 \quad 34.8$

Exclusive dependence on crack

Exclusive dependence on marijuana

Alcohol abuse

$26 \quad 7.4$

Cocaine abuse

$17 \quad 4.8$

Crack abuse

$6 \quad 1.7$

Marijuana abuse

14.5

Multiple PAS abuse

\section{Psychiatric Comorbidity}

$\begin{array}{rr}126 & 36 \\ 56 & 16 \\ 35 & 10 \\ 16 & 4.5 \\ 11 & 3.1 \\ 5 & 1.4 \\ 3 & 0.8\end{array}$

Patients with diagnoses related to the use of PAS totaled $23.8 \%$ of the patients attended by the REU Psychiatric Department of the HC-UNICAMP in this period. Similar rates were found in a study in England $(28 \%)^{12}$ and the United States $(24.4 \%)^{13}$.

Throughout the study there was a marginal tendency towards the increase of the rate of admission of patients with PAS use disorders in the REU. The time of this study limits conclusions on this data. Future researchers may support the hypothesis that there is or not a proportional increase in the number of attendances of this population. In Brazil, a study which took place in the Psychiatric Emergency Unit of the Clinical Hospital of Ribeirão Preto-SP, ${ }^{14}$ analyzing medical care during 1988 to 1997 , pointed to a decrease in the proportion of non-psychotic disorders and a progressive increase in problems related to alcohol and drugs, schizophrenia and affective psychoses. These data reinforce the importance of better understanding of this population in order to provide care concerning their needs. A study conducted in the United States ${ }^{15}$ showed that the 
chance of needing medical care due to PAS increased 10 -fold between patients of age between 18 and 24 years old and 2 times in males, when compared with the general population treated at the REU.

Patients with diagnoses related to the use of PAS differed from the other patients attended by Psychiatric Department of the REU HC-UNICAMP for being mostly male and younger when compared to patients treated due to other psychiatric diagnoses. The profiled delineated was similar to other profiles found in international studies. 7,13,16

In this study, the most frequently reported reasons for seeking treatment were psychiatric complaints other than the use of PAS (23.1\%), followed by the desire to treat/ hospitalize (20.8\%), and intoxication $(12,5 \%)$. These data show the importance of performing an active investigation regarding the use of PAS, since nearly a quarter of patients have not reported PAS use as a complaint. In a study conducted in the United States ${ }^{13}$ the most common reason of medical treatment among patients with disorders related to the use of PAS were mood symptoms (42.7\%), followed by anxiety symptoms $(26.1 \%)$ and conditions related to alcohol consumption (22.9\%). The high rates of desire to treat/hospitalize are particularly relevant in the current context of deficiency in PAS disorders treatment network.

Regarding the diagnostic profile, this study showed predominance $(38.5 \%)$ of dependence on multiple PAS. Although rates of cocaine use and addiction in brazilian population are much smaller than those of alcohol, ${ }^{17}$ when it comes to emergency care that rate is high, not only as exclusive use but also in the composition of multiple PAS use. The use of multiple PAS is an occurrence that currently constitutes more a rule than an exception. ${ }^{18}$ Dependents of multiple PAS have higher rates of recurring medical treatment in the emergency rooms, when compared to the population attended due to other PAS use disorders. ${ }^{16}$ In the present study, when we evaluate the dependence of an exclusive PAS, alcohol was the substance most frequently reported. The prevalence of alcohol was also found in most studies that took place in emergency rooms. ${ }^{7,12,19,20}$

Patients with diagnoses related to the use of PAS received more clinical and psychotropic medications than other patients attended by the Psychiatry in the REU. This picture is probably due to the fact that patients with clinical manifestations related to the use of PAS, such as intoxication and abstinence, are often in situations that require more intense clinical care. Regarding home prescriptions, patients with PAS related conditions received less prescription of antidepressants and antipsychotics than patients with other psychiatric diagnoses. This pattern was similar to the findings of a United States' study ${ }^{21}$ in which, nonprescription of psychotropic drugs had occurred most often among patients that were PAS users, among patients with suicidal ideation and among those who already had an existing outpatient psychiatrist. Nevertheless, in the present study patients with PAS related disorders received more benzodiazepines home prescriptions, to avoid abstinence and craving symptoms, and B vitamins' (B complex and thiamine) home prescriptions, to avoid $B$ hypovitaminosis.

When comparing the referrals for patients with conditions related to the use of PAS with other patients treated by the Psychiatric Department, it was found that, as expected, the former were more referred to CAPS-AD, for the Outpatient Clinic for Psychoactive Substances at the Clinical Hospital (ASPA) and hospitalization. Moreover, the rate of referrals to primary healthcare was much lower among those treated with disorders related to the use of PAS. This suggests that patients with clinical manifestations related to the use of PAS are probably considered more serious than other psychiatric diagnoses, therefore being more often referred to specialized services. The primary health care network, as well as the emergency room, is considered a propitious environment for detecting patients with problems related to PAS use disorders. ${ }^{10}$ Patients with PAS dependence and comorbidities are preferentially referred for specialized services. It is critical that the referral is done by considering the severity and needs of each patient. ${ }^{22}$

The present study showed that $36 \%$ of patients presented some kind of psychiatric comorbidity. In a study conducted in the United States, ${ }^{13}$ whereas patients with disorders related to the use of PAS with psychiatric comorbidity were responsible for $43 \%$ of psychiatric emergency care, patients with PAS disorders without comorbidity accounted for $29.3 \%$ of the psychiatric care.

A study evaluating the association between psychiatric comorbidity and PAS use disorders in 
patients attended in the Emergency Rooms ${ }^{16}$ showed that patients using multiple PAS were more likely to have other psychiatric diagnosis $(21.2 \%)$, followed by users with disorders due to cocaine use $(14.3 \%)$ and alcohol dependence $(14.1 \%)$. Patients with a primary diagnosis of PAS use disorders had on average 2.5 visits to emergency rooms in 4 years, while patients with comorbidities had 5.2 visits.

It is important to consider some limitations of this study. The first one refers to the incompleteness of information on the medical records, notably regarding social demographic variables, probably considered less essential when compared to the clinical data, essential for decision making in the context of emergency. This difficulty was also observed in other studies made in emergency services. ${ }^{9}$ This problem limits the data collection, resulting in high rates of missing data and hindering the descriptive analyzes and the establishment of correlations.

Another limitation was the lack of standardization of diagnoses made in the Psychiatric Emergency Department, which needed its establishment retrospectively by analyzing medical records; although it has been done after the pilot phase and the consensus of three psychiatrists, there is no equivalence in the diagnosis made at the moment when treatment was provided.

The limitations presented suggest caution when extrapolating the data concerning services with different characteristics than those shown.

Despite these limitations, this study contributes with national data about a topic that, although epidemiological and clinical relevant, is still sparsely researched in our midst. The possibility to understand the emergency patients' profile allows the better training of staff and building an effective health care network, critical for the outpatient follow-up.

A health care service should acutely know the profile of the target population, its potential, and the socio-cultural context that surrounds it. It is also necessary to plan for the future of the service, monitor implementation and assess the results in a constant and systematic way. ${ }^{14}$ Given the tendency of the increasing demand for medical care regarding clinical manifestations related to PAS use disorders, this study contributed with brazilian data on the detailed profile of this population through social demographic characterization and clinical particularities. Therefore, this research hopes to assist in the planning of actions to treat patients with PAS use disorders seeking emergency services, optimizing the care services in accordance with the characteristics described.

\section{Conclusion}

The results of this study show that patients attended by the ER Psychiatry due to PAS use disorders represented $23.8 \%$ of total psychiatric attendance and the profile was composed mostly of men and younger than other patients treated by Psychiatry. Regarding the source of referral, both groups came mostly from spontaneous demand, although patients with PAS use disorders came more from other services (therapeutic communities) than the other patients. Patients with PAS use disorders were more referred to specialized outpatient clinics and less for basic health care network than patients with other diagnoses. In the description of the care given to patients with PAS use disorders, the main reason for seeking treatment was psychiatric complaints other than the use of PAS, followed by the desire to treat/hospitalize and intoxication. Regarding the diagnostic profile, multiple PAS dependence was predominant, followed by exclusive alcohol dependence.

\section{References}

1. World Health Organization. Global Health Risks. Mortality and burden of disease attributable to selected major risks [Internet]. Geneve, Switzerland: WHO; 2009. Available from: http:// www.who.int/healthinfo/global_burden_disease/ GlobalHealthRisks_report_full.pdf

2. Bertanha D, Netto AR. Tabagismo, alcoolismo em pacientes que frequentam um serviço de fisioterapia do Sistema Único de Saúde. Medicina (Ribeirão Preto. Online) [Internet]. 2012;47(1):87-95. Available from: http://revista.fmrp.usp.br/ 2012/vol45n1/ao_Tabagismo alcoolismo em pacientes que frequentam fisioterapia.pdf

3. World Health Organization. Global Status Report on Alcohol and Health [Internet]. Geneve, Switzerland: WHO; 2011. Available from: http://www.who.int/substance_abuse/publications/ global_alcohol_report/msbgsruprofiles.pdf

4. UNODC (United Nations Office on Drugs and Crime). World Drug Report [Internet]. World Drug Report. 2012 [cited 2014 Sep 23]. Available from: http://www.unodc.org/documents/dataand analysis/WDR2012/WDR_2012_web_small.pdf 
5. French MT, Fang H, Balsa Al. Longitudinal analysis of changes in illicit drug use and health services utilization. Health Serv Res. [Internet]. 2011 Jun [cited 2014 Sep 15];46(3):877-99. Available from: http://www.pubmedcentral.nih.gov/articleren der.fcgi?artid=3087824\&tool=pmcentrez\& rendertype $=$ abstract

6. Hungerford DW, Williams JM, Furbee PM, Manley WG, Helmkamp JC, Horn K, et al. Feasibility of screening and intervention for alcohol problems among young adults in the ED. Am J Emerg Med. [Internet]. 2003 Jan [cited 2014 Sep 23];21(1):14-22. Available from: http://www.ncbi.nlm.nih.gov/ pubmed/12563573

7. Brubacher JR, Mabie A, Ngo M, Abu-Laban RB, Buchanan J, Shenton T, et al. Substance-related problems in patients visiting an urban Canadian emergency department. CJEM [Internet]. 2008 May [cited 2014 Sep 23];10(3):198-204. Available from: http://www.ncbi.nlm.nih.gov/pubmed/19019269

8. Larkin GL, Claassen CA, Emond JA, Pelletier AJ, Camargo CA. Trends in U.S. emergency department visits for mental health conditions, 1992 to 2001. Psychiatr Ser. [Internet]. 2005 Jun [cited 2014 Sep 20];56(6):671-7. Available from: http:// www.ncbi.nlm.nih.gov/pubmed/15939942

9. Lambert MT, LePage JP, Schmitt AL. Five-year outcomes following psychiatric consultation to a tertiary care emergency room. Am J Psychiatr. [Internet]. 2003 Jul [cited 2014 Sep 23];160(7):1350-3. Available from: http:// www.ncbi.nlm.nih.gov/pubmed/12832256

10. Cherpitel CJ, Ye Y. Trends in alcohol- and drug-related ED and primary care visits: data from three US National Surveys (1995-2005). Am J Drug Alcohol Abus. [Internet]. 2008 Jan [cited 2014 Sep 23];34(5):576-83. Available from: http:// www.pubmedcentral.nih.gov/articlerender.fcgi?artid=2770240 \&tool=pmcentrez\&rendertype=abstract

11. Gomide MFS, Pinto IC, Gomide DMP, Zacharias FCM. Perfil de usuários em um serviço de pronto-atendimento. Medicina (Ribeirão Preto. Online). [Internet]. 2012;45(1):31-8. Available from: http://revista.fmrp.usp.br/2012/vol45n1/ao_Perfil de usurios em um servico de pronto atendimento.pdf

12. Spurrell M, Hatfield B, Perry A. Characteristics of patients presenting for emergency psychiatric assessment at an English hospital. Psychiatr Ser. [Internet]. 2003 Feb [cited 2014 Sep 23];54(2):240-5. Available from: http://www.ncbi.nlm.nih.gov/ pubmed/12556607

13. Owens PL, Mutter R, Stocks C. Mental health and substance abuse-related emergency department visits among adults [Internet]. HCUP Statistical Brief 92, editor. Rockville: Agency for health care Research and Quality; 2010. Available from: http://www.hcup-us.ahrq.gov/reports/statbriefs/sb92.pdf
14. Del-Ben CM, Marques JMA, Sponholz Jr A, Zuardi AW. Políticas de saúde mental e mudanças na demanda de serviços de emergência. Rev Saude Publica. [Internet]. Faculdade de Saúde Pública da Universidade de São Paulo; 1999 Oct [cited 2014 Sep 23];33(5):470-6. Available from: http:// www.scielo.br/scielo.php?script=sci_arttext\&pid=S0034$89101999000500006 \&$ Ing $=e n \& n r m=i s o \& t l n g=p t$

15. Rockett IRH, Putnam SL, Jia H, Smith GS. Assessing substance abuse treatment need: a statewide hospital emergency department study. Ann Emerg Med. [Internet]. 2003 Jun [cited 2014 Sep 23];41(6):802-13. Available from: http://www.ncbi. nlm.nih.gov/pubmed/12764335

16. Curran GM, Sullivan G, Williams K, Han X, Allee E, Kotrla KJ. The association of psychiatric comorbidity and use of the emergency department among persons with substance use disorders: an observational cohort study. BMC emerg. med. (Online).[Internet]. 2008 Jan [cited 2014 Sep 7];8(1):17. Available from: http://www.biomedcentral.com/1471-227X/8/17

17. Vigitel Brasil 2011. Examination of risk factors in chronic diseases through telephone survey. [Internet]. Brasília; 2012. Available from: http://portalsaude.saude.gov.br/portalsaude/ arquivos/pdf/2012/Ago/22/vigitel_2011_final_0812.pdf

18. Montoya ID, McCann DJ. Drugs of abuse: management of intoxication and antidotes. EXS. [Internet]. 2010 Jan [cited 2014 Sep 23];100:519-41. Available from: http:// www.ncbi.nlm.nih.gov/pubmed/20358694

19. Santos ME, do Amor JA, Del-Ben CM, Zuardi AW. [Psychiatric emergency service in a university general hospital: a prospective study]. Rev Saude Publica. [Internet]. 2000 Oct [cited 2014 Sep 23];34(5):468-74. Available from: http:// www.ncbi.nlm.nih.gov/pubmed/11105110

20. Breton AR, Taira DA, Burns E, O'Leary J, Chung RS. Followup services after an emergency department visit for substance abuse. Am J Manag Care. [Internet]. 2007 Sep [cited 2014 Sep 23];13(9):497-505. Available from: http:// www.ncbi.nlm.nih.gov/pubmed/17803363

21. Ernst CL, Bird SA, Goldberg JF, Ghaemi SN. The prescription of psychotropic medications for patients discharged from a psychiatric emergency service. J Clin Psychiatr. [Internet]. 2006 May [cited 2014 Sep 23];67(5):720-6. Available from: http://www.ncbi.nlm.nih.gov/pubmed/16841621

22. Ritsher JB, Moos RH, Finney JW. Relationship of treatment orientation and continuing care to remission among substance abuse patients. Psychiatr Ser. [Internet]. 2002 May [cited 2014 Sep 23];53(5):595-601. Available from: http:// www.ncbi.nlm.nih.gov/pubmed/11986510 